\title{
Labio-Jugal Squamous Cell Carcinoma on HIV Site: Surgical Excision and Reconstruction with a Musculocutaneous Flap of the Pectoralis Major: A Case Report
}

\author{
Saliou Adam ${ }^{1,2^{*}}$, Hamza Dolès Sama ${ }^{3}$, Essobozou Plaoudézina Pegbessou ${ }^{4}$, \\ Yao Messanvi Akpoto5, Palakina Agoda', Winga Foma², Haréfétéguéna Bissa1,2, \\ Bathokédéou Amana², Mohaman Awalou Djibril ${ }^{5}$, Essohanam Boko4 ${ }^{4}$, Eyawèlohn Kpemissi2 \\ ${ }^{1}$ Department of Stomatology and Maxillofacial Surgery, Sylvanus Olympio University Teaching Hospital of Lomé, Togo, Lomé \\ ${ }^{2}$ Department of ENT, Sylvanus Olympio University Teaching Hospital of Lomé, Togo, Lomé \\ ${ }^{3}$ Department of Anesthesia and Intensive Care, Sylvanus Olympio University Teaching Hospital of Lomé, Togo, Lomé \\ ${ }^{4}$ Department of ENT, Campus University Teaching Hospital of Lomé, Togo, Lomé \\ ${ }^{5}$ Department of Military Medical, Sylvanus Olympio University Teaching Hospital of Lomé, Togo, Lomé \\ ${ }^{6}$ Department of Stomatology, Campus University Teaching Hospital of Lomé, Togo, Lomé \\ Email: *saliou.adam1@yahoo.com
}

How to cite this paper: Adam, S., Sama, H.D., Pegbessou, E.P., Akpoto, Y.M., Agoda, P., Foma, W., Bissa, H., Amana, B., Djibril, M.A., Boko, E. and Kpemissi, E. (2021) LabioJugal Squamous Cell Carcinoma on HIV Site: Surgical Excision and Reconstruction with a Musculocutaneous Flap of the Pectoralis Major: A Case Report. Open Journal of Stomatology, 11, 460-466.

https://doi.org/10.4236/ojst.2021.1111041

Received: October 9, 2021

Accepted: November 10, 2021

Published: November 23, 2021

Copyright ( 2021 by author(s) and Scientific Research Publishing Inc. This work is licensed under the Creative Commons Attribution International License (CC BY 4.0).

http://creativecommons.org/licenses/by/4.0/ (c) (i) Open Access

\begin{abstract}
Introduction: Malignant skin tumors are very frequent lesions, induced by sustained sun exposure. Cutaneous squamous cell carcinoma is a dangerous cancer of the skin. It's more frequent in white people than black people. Squamous cell carcinomas sometimes pose a real problem of local reconstruction after their removal. Reconstructions may involve the production of regional pedunculated flaps to repair the loss of substance. We report the case of a labio-jugal squamous cell carcinoma in an HIV-positive patient. The excision of the tumor required repair by a musculocutaneous flap of the pectoralis major. The aim of this paper is to show the dangerousness of that cancer, the particularity of its location around the mouth. We also want to call for a reflection about the recurrence of that disease on HIV infection ground, despite correct resection. Clinical Case: This was a 47-year-old HIV-positive patient on antiretroviral therapy (ARVs), treated 23 years ago for pulmonary tuberculosis. He presented with an ulcerated lower lip wound extending to the right labial commissure, right cheek, and the right lateral third of the upper lip. This lesion had progressed for about 6 months without a tendency to spontaneous healing. There was no palpable lymphadenopathy, especially in the cervicofacial region. The biopsy of the lower labial lesion concluded that it was a differentiated, mature, infiltrating squamous cell carcinoma. The craniofacial
\end{abstract}


CT scan did not note any regional tumor invasion. We indicated tumor excision, functional lymph node dissection, and reconstruction by a flap of the pectoralis major muscle. The operative procedure was performed under general anesthesia. The edge cuts after carcinoma removal were healthy. Three months later, the patient is seen again with a local right submandibular recurrence. Radiotherapy was offered to him. Discussion: Squamous cell carcinomas are frequent in sub-Saharan Africa with preferential localization to oropharynx and oral cavity. More and more viral infections such as HIV, HBV and HCV are implicated in the occurrence of squamous cell carcinomas of the ENT and neck and facial sphere. HIV appears to be a contributing factor in young populations. Multidisciplinary management with anti-infective treatment coupled with new therapies could reduce the risk of recurrence and metastases.

\section{Keywords}

Squamous Cell Carcinoma, Labio-Jugal, Pectoralis Major Flap, HIV Site

\section{Introduction}

Malignant skin tumors are very common, favored by sustained sun exposure. Cutaneous squamous cell carcinoma is a dangerous cancer of the skin. It's more frequent in white people than black people. Melanin, the pigment responsible for skin color, is protective against carcinogenic ultraviolet radiation [1]. Cutaneous squamous cell carcinomas pose a real problem of local reconstruction after their large excision. While alcohol and tobacco are the main contributing factors for squamous cell carcinoma of the ENT sphere, infection with Human Papilloma Virus (HPV) has been implicated as another contributing factor [2]. The increasing incidence of oral-genital infection in a new population of younger patients sometimes not exposed to tobacco or alcohol, but infected with the Human Immunodeficiency Virus (HIV) has been highlighted. Squamous cell carcinoma is a dangerous cancer of the skin [3]. The aim of this paper is to show the dangerousness of that cancer, the particularity of its location around the mouth and the necessity of repairing of the large loss of substance after resection by the musculocutanneous flap of the pectoralis major. We also want to call for a reflection about the recurrence of that affection on HIV infection ground, despite correct resection.

\section{Clinical Case}

We report a case of a dragging right labio-jugal ulcer-bud wound, evolving for 6 months in a 47-year-old patient. This HIV positive patient is on antiretroviral therapy (ARV) and was treated 23 years ago for pulmonary tuberculosis. The history of the disease recalls an episodic appearance of skin lesions of the lower lip which healed spontaneously. For the past six months, a progressive extension 
has appeared to the right labial commissure, right cheek and right lateral third of the upper lip without any tendency for spontaneous healing.

During the consultation in the stomatology department, the facial clinical examination revealed an ulcerated wound and budding, taking the entire lower lip, the right labial commissure and the right lateral third of the upper lip.

This wound had a dirty bottom and perilesional induration (Figure 1). There was not any palpable lymphadenopathy and trismus. The endo-oral examination found a macroscopically uninjured labial vestibule. The biopsy of the lower labial lesion revealed a differentiated, mature and infiltrating squamous cell carcinoma (Figure 2). The craniofacial CT scan showed an absence of regional tumor invasion allowing the tumor to be classified as T3N0M0. The indication of tumor excision with functional lymph node dissection was made. The patient was classified ASA 3. Under general anesthesia with nasotracheal intubation, we performed tumor resection with margins of 10 millimeters and lymph node dissection of areas I, II, III following the Sébileau-Carréga type incision (Figure 3). On exploration, lymphadenopathy was found in sectors $\mathrm{Ib}$ and Ia. The cuts of the banks after surgery were healthy. The reconstruction was done by a musculocutaneous flap of the pectoralis major muscle. The flap was cut on a pattern reproducing the loss of substance (Figure 4(A)) and was sutured at the recipient site in three planes. The donor site was closed by direct suture on a suction Redon (Figure 4(B) and Figure 4(C)). A nasogastric feeding tube was placed for a
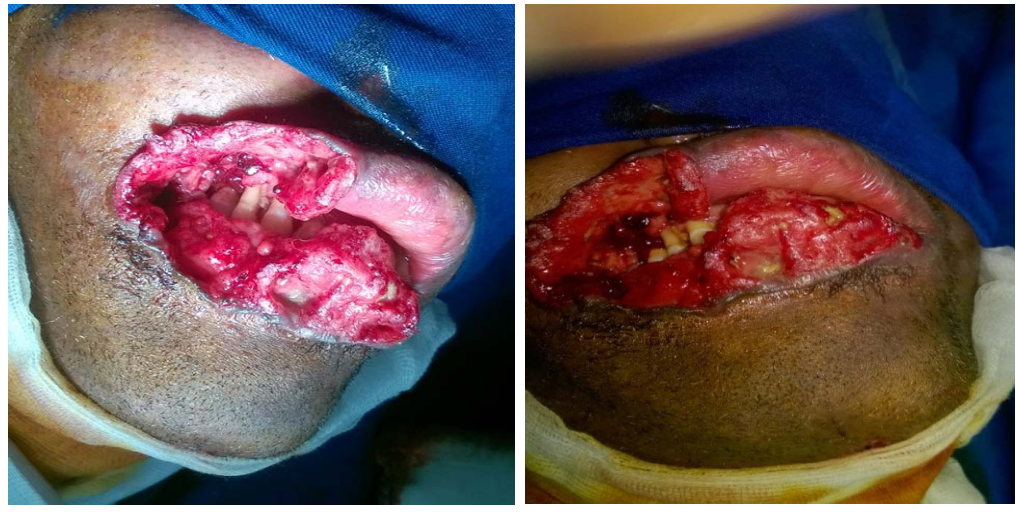

Figure 1. Right labio-jugal ulcerative bud tumor.
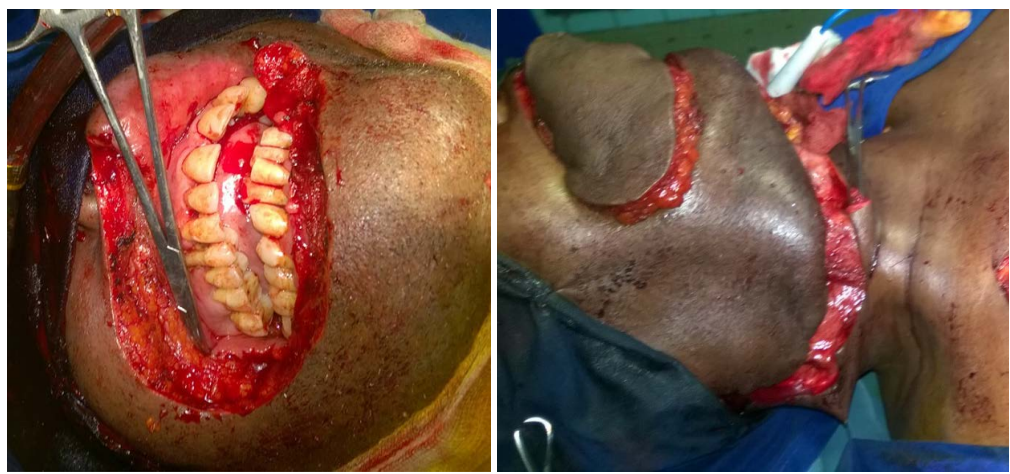

Figure 2. Excision with a margin of $10 \mathrm{~mm}$ and lymph node dissection. 


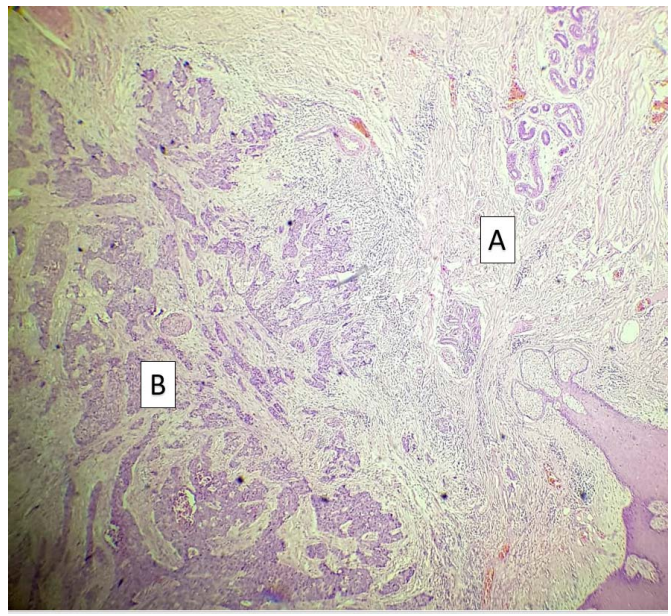

Figure 3. Histological appearance of invasive squamous cell carcinoma: Note normal skin tissue (A) infiltrated by moderately to poorly differentiated squamous cell carcinoma (B) (HE; x4).

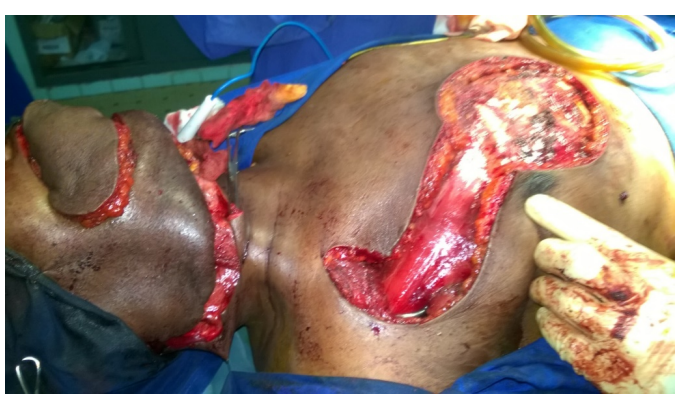

(A)

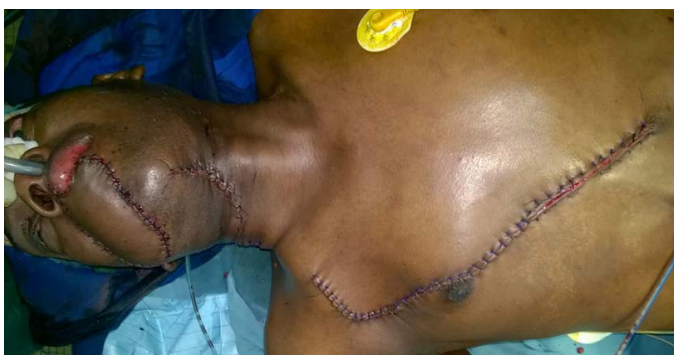

(B)

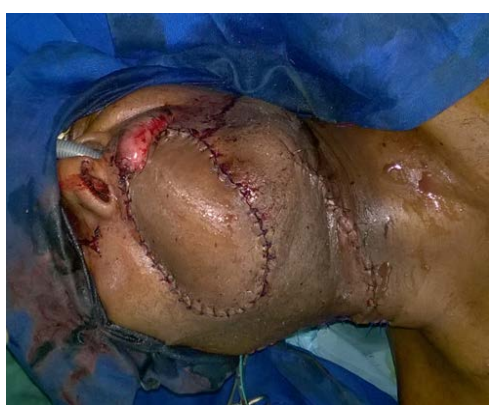

(C)

Figure 4. (A) Reconstruction with the musculocutaneous flap of the pectoralis major muscle: flap removal; (B) and (C) Reconstruction with the musculocutaneous flap of the pectoralis major muscle: flap placement and closure. 
period of 21 days to ensure high-calorie and high-protein enteral nutrition. The patient was treated by antibiotics, anti inflammatories, and drogs against pain. The mouth cleaning was made with Polyvidone iodine, we locked carefully after flap vitality The postoperative consequences were marked by a local right submandibular recurrence 3 months later. Complementary radiotherapy was offered to the patient, but the patient had to move to another country, because of lack of that treatment in our health care center.

\section{Discussion}

Squamous cell carcinomas are frequent in sub-Saharan Africa with preferential localization at the oropharyngeal and oral level in $90 \%$ of cases [4]. Invasive squamous cell carcinoma represented $20 \%$ of skin cancer in people with albinism in Togo [5]. More and more viral infections such as HIV, HBV and HCV are implicated in the occurrence of squamous cell carcinomas of the ENT and cervicofacial sphere [6] [7]. HIV appears to be a contributing factor in young populations according to FMA Butt et al. [8]. The coexistence of HPV infection, although not always constant, exists in these patients and may have a role in the malignant degeneration of these tumors [9]. These lesions often pose a problem of therapeutic management. Among other things, international recommendations have been proposed [10] as well as neoadjuvant chemotherapy [11] and a genomic approach [12]. One of the problems with this care is often surgery. In our patient, we performed a resection respecting a safety margin according to standards [13] with a functional lymph node dissection [14]. Despite therapeutic advances, surgical resection and reconstruction at the same time of surgery, about squamous cell carcinomas and oropharyngeal and facial cancers in general remains a subject of debate [15] [16]. Functional sequelae are not uncommon [17]. Behavioral preventive measures have been mentioned [18]. HPV vaccination in people at risk could also have a protective role [19]. This multidisciplinary management consisting of anti-infective treatment coupled with new therapies [20] could reduce the risk of recurrence and metastases. Moreover, this case seems unique to us due to the unexpected recurrence in this HIV positive field. One of the limitations of this paper is that the patient moved away from the hospital to complete his treatment by X-Ray-therapy in another country, and did not return back to us for the rest of the treatment and postoperative check.

\section{Conclusion}

This clinical case shows the recurrent problem of complete management of malignant tumors. The availability of an extemporaneous histological examination of the cross-sections of the margins during tumor surgery could contribute to better management of these lesions and reduce the risk of recurrence.

\section{Informed Consent}

We obtained consent from the patient and his parents to publish this case. 


\section{Conflicts of Interest}

We have no conflicts of interest about this study, and we have been approved by the ethical committee commission of the hospital before beginning this study.

\section{References}

[1] Saka, B., Akakpo, S.A., Teclessou, J.N., Gnossike, P., Adam, S., Mahamadou, G., Kassang, P., Elegbede, Y., Mouhari-Toure, A., Kombate, K. and Pitché, P. (2021) Skin Cancers in People with Albinism in Togo in 2019: Results of Two Rounds of National Mobile Skin Care Clinics. BMC Cancer, 21, 26. https://doi.org/10.1186/s12885-020-07747-8

[2] Zhang, H., Kim, S., Chen, Z., et al. (2017) Prognostic Biomarkers in Patients with Human Immunodeficiency Virus-Positive Disease with Head and Neck Squamous Cell Carcinoma. Head \& Neck, 39, 2433-2443. https://doi.org/10.1002/hed.24911

[3] Sami, A., Elimairi, I., Stanton, C., Ross, R.P. and Ryan, C.A. (2020) The Role of the Microbiome in Oral Squamous Cell Carcinoma with Insight into the MicrobiomeTreatment Axis. International Journal of Molecular Sciences, 21, 8061. https://doi.org/10.3390/ijms21218061

[4] Faggons, C.E., Mabedi, C., Shores, C.G., Gopal, S. (2015) Review: Head and Neck Squamous Cell Carcinoma in Sub-Saharan Africa. Malawi Medical Journal, 27, 79-87. https://doi.org/10.4314/mmj.v27i3.2

[5] Saka, B., Téclessou, J., Akakpo, S., Gnossiké, P., Doh, K., Adam, S., Mouhari-Touré, A., Garba, M., Kombaté, K. and Pitché, P. (2020) Histopathological Study of Skin Lesions in Individuals with Oculocutaneous Albinism in Togo in 2019. Journal of Skin Cancer, 2020, Article ID: 2361957. https://doi.org/10.1155/2020/2361957

[6] Nayyar, S.S., Thiagarajan, S., Malik, A., et al. (2020) Head and Neck Squamous Cell Carcinoma in HIV, HBV and HCV Seropositive Patients-Prognosis and Its Predictors. Journal of Cancer Research and Therapeutics, 16, 619-623. https://doi.org/10.4103/jcrt.JCRT_166 19

[7] Picard, A., Arowas, L., Piroth, L., et al. (2018) Head and Neck Squamous Cell Carcinoma in People Living with HIV in France. Médecine et Maladies Infectieuses, 48, 503-508. https://doi.org/10.1016/j.medmal.2018.05.002

[8] Butt, F.M.A., Chindia, M.L. and Rana, F. (2012) Oral Squamous Cell Carcinoma in Human Immunodeficiency Virus Positive Patients: Clinicopathological Audit. The Journal of Laryngology \& Otology, 126, 276-278. https://doi.org/10.1017/S0022215111002647

[9] Ceccarelli, M., Rullo, E.V., Facciolà, A., et al. (2018) Head and Neck Squamous Cell Carcinoma and Its Correlation with Human Papillomavirus in People Living with HIV: A Systematic Review. Oncotarget, 9, 17171-17180.

https://doi.org/10.18632/oncotarget.24660

[10] Cohen, E.E.W., Bell, R.B., Bifulco, C.B., et al. (2019) The Society for Immunotherapy of Cancer Consensus Statement on Immunotherapy for the Treatment of Squamous Cell Carcinoma of the Head and Neck (HNSCC). Journal for Immunotherapy of Cancer, 7, 184. https://doi.org/10.1186/s40425-019-0662-5

[11] Schoenfeld, J.D., Hanna, G.J., Jo, V.Y., et al. (2020) Neoadjuvant Nivolumab or Nivolumab plus Ipilimumab in Untreated Oral Cavity Squamous Cell Carcinoma: A Phase 2 Open-Label Randomized Clinical Trial. JAMA Oncology, 6, 1563-1570. https://doi.org/10.1001/jamaoncol.2020.2955

[12] Solomon, B., Young, R.J. and Rischin, D. (2018) Head and Neck Squamous Cell 
Carcinoma: Genomics and Emerging Biomarkers for Immunomodulatory Cancer Treatments. Seminars in Cancer Biology, 52, 228-240.

https://doi.org/10.1016/j.semcancer.2018.01.008

[13] Kuan, E.C., Clair, J.M.-S., Badran, K.W., et al. (2016) How Does Depth of Invasion Influence the Decision to Do a Neck Dissection in Clinically N0 Oral Cavity Cancer? Laryngoscope, 126, 5476. https://doi.org/10.1002/lary.25707

[14] González-García, R., Naval-Gías, L., Rodríguez-Campo, F.J., et al. (2008) Contralateral Lymph Neck Node Metastasis of Squamous Cell Carcinoma of the Oral Cavity: A Retrospective Analytic Study in 315 Patients. Journal of Oral and Maxillofacial Surgery, 66, 1390-1398. https://doi.org/10.1016/j.joms.2008.01.012

[15] Yao, C.M.K.L., Chang, E.I., Lai, S.Y., et al. (2019) Contemporary Approach to Locally Advanced Oral Cavity Squamous Cell Carcinoma. Current Oncology Reports, 21, 99. https://doi.org/10.1007/s11912-019-0845-8

[16] Maruo, T., Zenda, S. and Shinozaki, T. (2020) Comparison of Salvage Surgery for Recurrent or Residual Head and Neck Squamous Cell Carcinoma. Japanese Journal of Clinical Oncology, 50, 288-295. https://doi.org/10.1093/jico/hyz176

[17] Hsiang, C.-C., Chen, A.W.-G., Chen, C.-H., et al. (2019) Early Postoperative Oral Exercise Improves Swallowing Function among Patients with Oral Cavity Cancer: A Randomized Controlled Trial. Ear, Nose \& Throat Journal, 98, E73-E80. https://doi.org/10.1177/0145561319839822

[18] Thomson, P.J. (2018) Perspectives on Oral Squamous Cell Carcinoma PreventionProliferation, Position, Progression and Prediction. Journal of Oral Pathology \& Medicine, 47, 803-807. https://doi.org/10.1111/jop.12733

[19] Tumban, E. (2019) A Current Update on Human Papillomavirus-Associated Head and Neck Cancers. Viruses, 11, 922. https://doi.org/10.3390/v11100922

[20] Gao, F., Yin, P., Wu, Y., et al. (2021) Knockdown of RhoC Inhibits Oral Squamous Cell Carcinoma Cell Invasion and Metastasis via Regulation of HMGA2. Journal of Oncology, 1-12. https://doi.org/10.1155/2021/6644077 